\title{
IMPLEMENTATION OF ARTIFICIAL NEURAL NETWORK ALGORITHM ON VEHICLE REGISTRATION DATA
}

\author{
DR. P. Y. DESAI \\ Department of ICT \\ Veer Narmad South Gujarat University, Surat, India
}

\begin{abstract}
An Artificial Neural Network can be implemented to solve variety of problems. An Artificial Neural Network has been used in different domains like Finances, Marketing, Healthcare, Image Processing, Crime Detection, Weather Forecasting, Economics, Voice Recognition etc...In last few years, Government institutions around the world also started using an Artificial Neural Network on e-governance data. In this paper, an Artificial Neural Network is applied on Vehicle Registration Data to uncover interesting relationship among various attributes.
\end{abstract}

Keywords: Data Mining, Artificial Neural Network, Vehicle Registration

Cite this Article: Dr. P. Y. Desai, Implementation of Artificial Neural Network Algorithm on Vehicle Registration Data, International Journal of Advanced Research in Engineering and Technology, 10(1), 2019, pp 83-87.

http://iaeme.com/Home/issue/IJARET?Volume=10\&Issue $=1$

\section{INTRODUCTION}

Normally, e-governance data used only for Online Transaction Processing systems. It means that in most cases e-governance systems are only used for Insert, Update, Delete and Search operations. These systems contain gigabytes and terabytes of data but systems are not mined for getting novel trends and patterns from it. This paper proposed to use Artificial Neural Network on Vehicle Registration data to uncover hidden trends and relationship among various attributes. An Artificial Neural Network is inspired by the way biological nervous systems functions in human. To understand the basic functioning of a neural net, consider A1 and A2 as a set of neurons which transmits signals to another neuron B. In this example, A1 and A2 are input neurons and $\mathrm{B}$ is output neuron. Input neuron $\mathrm{A} 1$ and $\mathrm{A} 2$ are connected to output neuron $\mathrm{B}$ via weighted interconnection like $\mathrm{W} 1$ and $\mathrm{W} 2$. This neuron net architecture can be calculated in the following way:

$$
b_{i n}=a_{1} w_{1}+a_{2} w_{2}
$$

Where $\mathrm{a}_{1}$ and $\mathrm{a}_{2}$ are the activations of the input neurons $\mathrm{A} 1$ and $\mathrm{A} 2$. The output $\mathrm{b}$ of the output neuron $\mathrm{B}$ can be obtained by applying activation function over the net input. This function can be obtained as follows: 


$$
\boldsymbol{b}=\boldsymbol{f}\left(\boldsymbol{b}_{\text {in }}\right)
$$

This function is known as activation function [5] [6]. In this paper, various attributes related to Vehicle Registration data are considered as input neurons and out neurons. The Microsoft Neural Network algorithm is applied to create neural network from it.

\section{RESEARCH METHODOLOGY}

The Microsoft Neural Network algorithm uses Multilayer Perceptron Network [8]. Typically this contains three layers of neurons: Input layer, Hidden layer and Output layer [8]. In a Microsoft neural network algorithm, Input Layer pass forward inputs to the hidden layer and then it is further pass forward to output layer. The output neuron is a simple non-linear function of the sum of the inputs to the neuron [8].

The input neurons provide input to the Microsoft Neural Network algorithm. For Vehicle Registration data, several fields were selected as input neurons. These were City, Company Code, Owner Surname, Paid Status, Reg Year, Vehicle Type Id. The output neuron was selected for Vehicle Type Name attribute. This is required to predict buying pattern for particular Vehicle Type based on various input neurons.

The Microsoft Neural Network allows us to set certain parameters which determine how the algorithm will perform and generate neural network. The HIDDEN_NODE_RATIO parameter can be set to determine number of hidden layer. If we set HIDDEN_NODE_RATIO to 0, no hidden layer will be created. The MAXIMUM_STATES algorithm parameter restricts number of states for attributes. If some attributes crosses this parameter value, the most relevant states are selected and rest are ignored [8]. The default value for MAXIMUM_STATES is 100. The Table 1 contains some of the important parameters in the algorithm.

Table 1 Parameter settings of the algorithm

\begin{tabular}{|c|c|c|c|}
\hline Name of the parameter & Description & Default Values & Justification \\
\hline MAXIMUM_INPUT_ATTRIBUTES & $\begin{array}{c}\text { Maximum input } \\
\text { attributes }\end{array}$ & 255 & $\begin{array}{c}\text { Unchanged as } \\
\text { input attribute } \\
\text { are less }\end{array}$ \\
\hline MAXIMUM_OUTPUT_ATTRIBUTES & $\begin{array}{c}\text { Maximum output } \\
\text { attributes }\end{array}$ & 255 & $\begin{array}{c}\text { Unchanged as } \\
\text { output attribute } \\
\text { are less }\end{array}$ \\
\hline MAXIMUM_STATES & $\begin{array}{c}\text { Maximum states of } \\
\text { attribute values }\end{array}$ & 100 & $\begin{array}{c}\text { Changed to 25 } \\
\text { to focus on only } \\
\text { important states } \\
\text { of input } \\
\text { attribute. }\end{array}$ \\
\hline SAMPLE_SIZE & $\begin{array}{c}\text { Number cases to } \\
\text { consider for training } \\
\text { model }\end{array}$ & 10000 & $\begin{array}{c}\text { Unchanged as it } \\
\text { is sufficient for } \\
\text { training model. }\end{array}$ \\
\hline HIDDEN_NODE_RATIO & Ratio of hidden neuron & 4 & $\begin{array}{c}\text { Unchanged as } \\
\text { ratio of input } \\
\text { and output } \\
\text { neurons is less } \\
\text { than 4. }\end{array}$ \\
\hline
\end{tabular}

The Microsoft Neural Network first extracts data from the Vehicle Registration Data Source. From this extracted data, some percentage of data is reserved for measuring the accuracy of the model. This is referred as Holdout Data. The algorithm checks for the accuracy after every iteration through training data. The algorithm stops once it is observed that accuracy is not increasing [8]. Considering algorithm functioning and parameter setting, the neural network was generated for Vehicle Registration data. 


\section{RESULTS}

As discussed in the research methodology section, input attributes were City, Company Code, Owner Surname, Paid Status, Reg Year, Vehicle Type Id and output attribute was Vehicle Type Name attribute. The Figure 1 shows interesting relationship among various states of Vehicle Type Name and Owner Surname. The Figure 1 indicates that citizen with "Naik" Owner Surname favours purchase of MOPED_SCOOTER whereas citizen with "KHAN" Owner Surname favours purchase of COMMERCIAL Vehicle Type. The Discrimination Viewer's result is shown in the Table 2.

Table 2 Discrimination Viewer Result for Owner Surname State = "KHAN" and "Naik"

\begin{tabular}{|c|c|c|c|}
\hline \multicolumn{1}{|c|}{ Attribute } & Value & Favors KHANFavors Naik \\
\hline Vehicle Type Name MOPED SCOOTER & & 100 \\
\hline Vehicle Type Name & COMMERCIAL & 93.05 & \\
\hline Vehicle Type Name & MOTORCYCLE & 15.27 & \\
\hline Vehicle Type Name & CAR & & 4.09 \\
\hline Vehicle Type Name & AUTORICKSHAW & & 3.04 \\
\hline
\end{tabular}

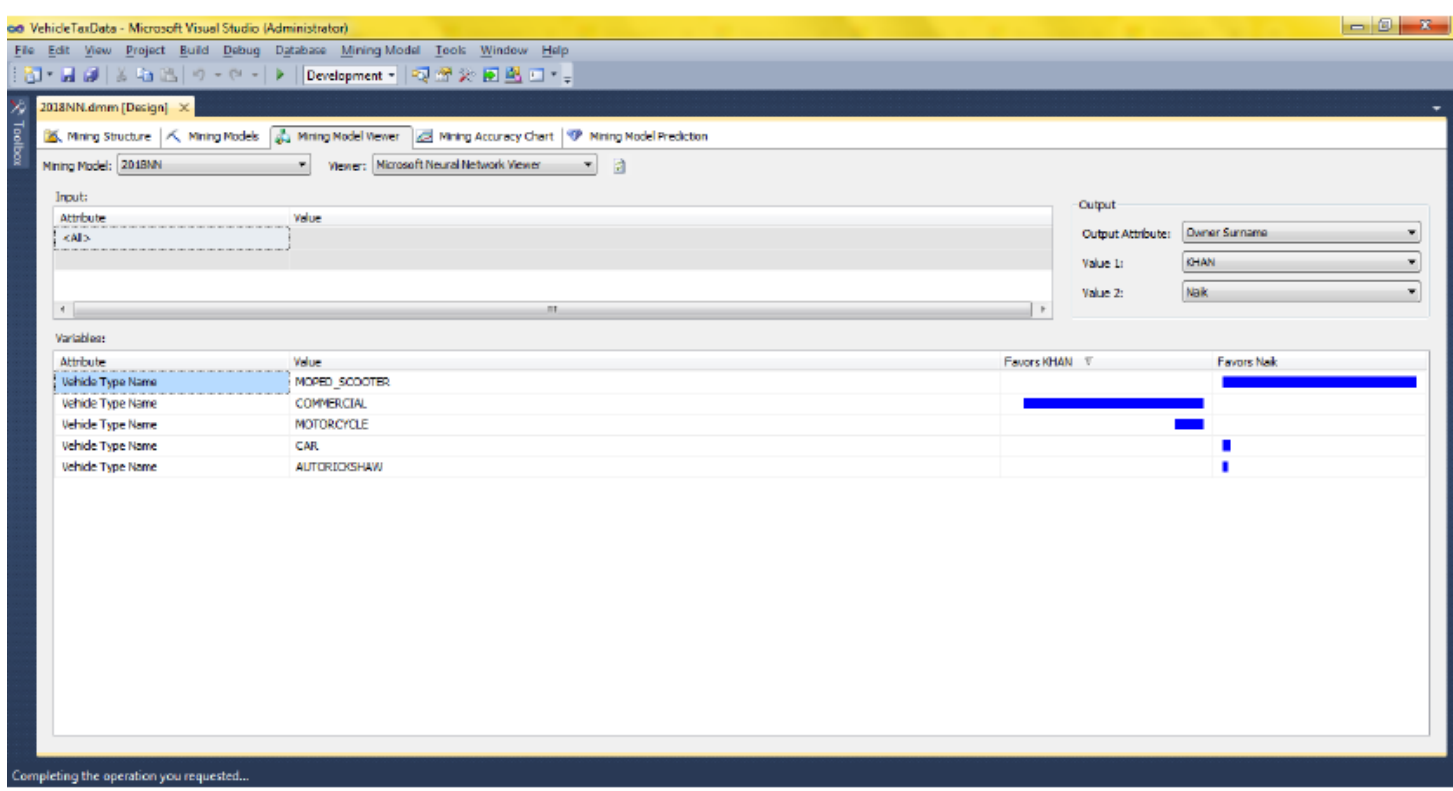

Figure 1. Discrimination Viewer Result for Owner Surname State = "KHAN" and "Naik"

Similarly, for Owner Surname State "DUBY" and "AGRAWAL" results are shown in Table 3 and Figure 2.

Table 3 Discrimination Viewer Result for Owner Surname State = "DUBY" and "AGRAWAL"

\begin{tabular}{|l|c|c|c|}
\hline \multicolumn{1}{|c|}{ Attribute } & Value & Favors DUBEY Favors AGRAWAL \\
\hline Vehicle Type Name & AUTORICKSHAW & 100 & \\
\hline Vehicle Type Name & COMMERCIAL & 58.86 & \\
\hline Vehicle Type Name & MOTORCYCLE & & 50.73 \\
\hline Vehicle Type Name & CAR & 41.17 & \\
\hline \multicolumn{2}{|l|}{ Vehicle Type Name MOPED SCOOTER } & & 38.26 \\
\hline
\end{tabular}




\section{Dr. P. Y. Desai}

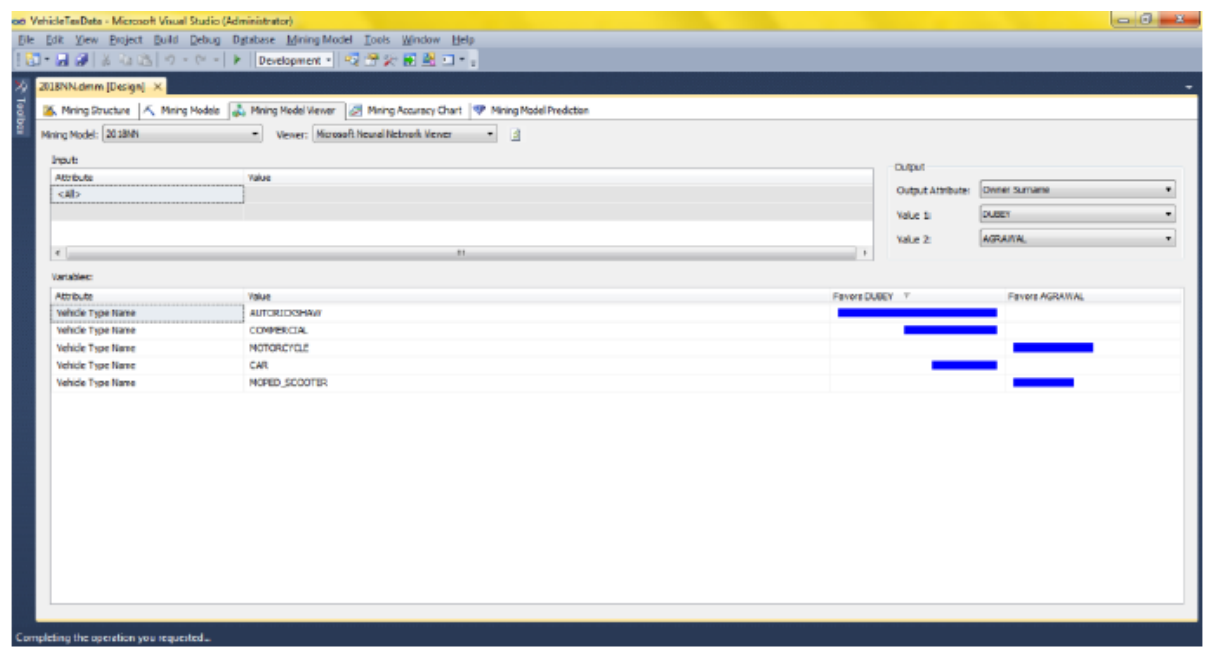

Figure 2. Discrimination Viewer Result for Owner Surname State = "DUBY" and "AGRAWAL"

For Owner Surname State "NOORANI" and "JOSHI" results are shown in Table 4 and Figure 3.

Table 4 Discrimination Viewer Result for Owner Surname State = "NOORANI" and "JOSHI"

\begin{tabular}{|c|c|c|c|}
\hline Attribute & Value & Favors NOORANI & Favors JOSHI \\
\hline Vehicle Type Name & AUTORICKSHAW & 100 & \\
\hline Vehicle Type Name & MOPED SCOOTER & & 46.02 \\
\hline Vehicle Type Name & CAR & & 39.59 \\
\hline Vehicle Type Name & COMMERCIAL & & 28.95 \\
\hline Vehicle Type Name & MOTORCYCLE & 21.56 & \\
\hline
\end{tabular}

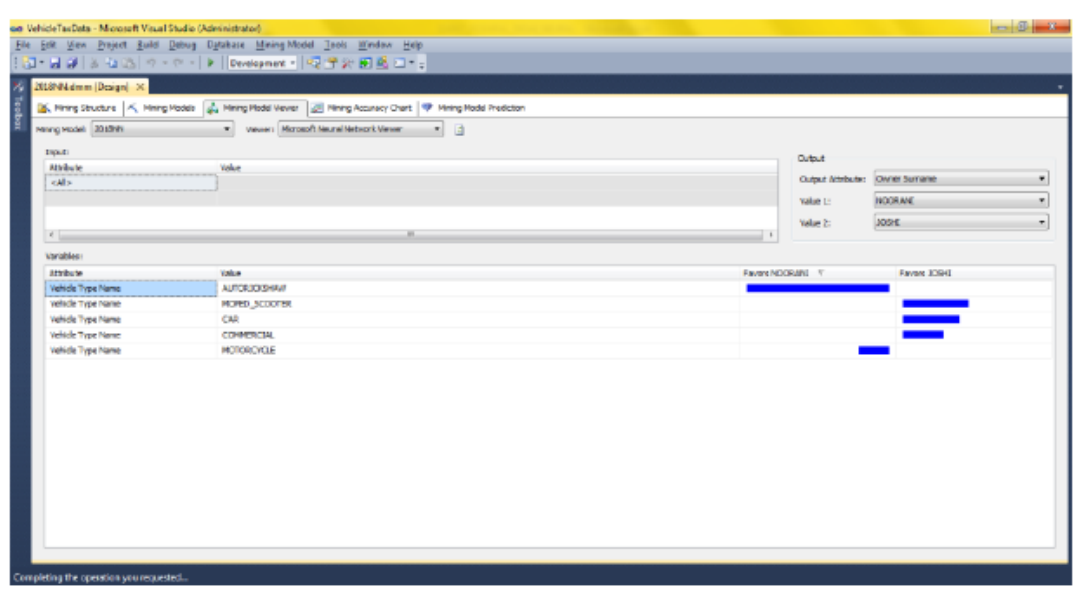

Figure 3. Discrimination Viewer Result for Owner Surname State = "NOORANI" and "JOSHI"

\section{CONCLUSION}

The Microsoft Neural Network implementation provide great insight into Vehicle Registration Data for analysis of buying patterns considering Owner Surname.

\section{REFERENCES}

[1] Dr. Nabeel T. Alshohybe and Dr. Ghaleb H. Al-Gaphari, Diagnosis for Heart Disease Using Neural Network IRACST - International Journal of Computer Science and Information Technology \& Security (IJCSITS), ISSN: 2249-9555, Vol.6, No.6, Nov-Dec 2016. 
[2] Karan Manchandia and Navdeep Khare, Implementation of Student Performance Evaluation Through Supervised Learning Using Neural Network, International Journal of Engineering Sciences \& Research Technology, ISSN: 2277-9655, March, 2017.

[3] Dr Vinodini Katiyaar and Ina Kapoor Sharma, Use of Data Mining \& Neural Network in Commercial Application, Vinodhini Katiyaar et al, / (IJCSIT) International Journal of Computer Science and Information Technologies, Vol. 3 (3), 2012,4041 - 4049.

[4] Lina L. Dhande and Dr. Prof. Girish K. Patnaik, Analyzing Sentiment of Movie Review Data using Naive Bayes Neural Classifier, International Journal of Emerging Trends \& Technology in Computer Science (IJETTCS), Volume 3, Issue 4 July-August 2014, ISSN 2278-6856.

[5] S.N. Sivanandam and S.N. Deepa, Principals of Soft Computing, $3^{\text {rd }}$ Edition, Wily, 2018, pp. 930 .

[6] Arun K Pujari, Data Mining Techniques, $2^{\text {nd }}$ Edition, University Press, pp 233-256.

[7] Clare, L., Pottie, G. and Agre, J. Self-Organizing Distributed Sensor Networks. Proceedings SPIE Conference Unattended Ground Sensor Technologies and Applications, Orlando, 3713, 1999 pp. 229-237.

[8] Microsoft Neural Network Algorithm Technical Reference.

[9] https://docs.microsoft.com/en-us/sq1/analysis-services/data-mining/microsoft-neural-networkalgorithm-technical-reference?view=sql-server-2017

[10] Microsoft Neural Network Algorithm

[11] https://docs.microsoft.com/en-us/sq1/analysis-services/data-mining/microsoft-neural-networkalgorithm?view=sql-server-2017

[12] Browse a Model Using the Microsoft Neural Network Viewer

[13] https://docs.microsoft.com/en-us/sq1/analysis-services/data-mining/browse-a-model-using-themicrosoft-neural-network-viewer?view=sql-server-2017

[14] Dharmendra Kumar singh, Dr.Moushmi Kar and Dr.A.S.Zadgaonkar, Analysis of Generated Harmonics Due to Transformer Load on Power System Using Artificial Neural Network, International Journal of Electrical Engineering and Technology (IJEET), Volume 4, Issue 1, January- February (2013), pp. 81-90

[15] Dr. E. Priyadarshini, Analysis of the Performance of Artificial Neural Network Technique for Forecasting Mutual Fund Net Asset Values, International Journal of Management (IJM), Volume 4, Issue 6, November - December (2013), pp. 217-220

[16] Muhammad Zaki, SPR Wardani, Tommy Ilyas, Analysis Ultimate Bearing Capacity on Bored Pile with Using Artificial Neural Network, International Journal of Civil Engineering and Technology 10(3), 2019, pp. 2036-2045

[17] Manoj B. Karathiya, Deven J. Patel and Parag C. Shukla, Application of Artificial Neural Network in Metropolitan Landscape Water Eminence Assessment, International Journal of Computer Engineering and Technology (IJCET), Volume 4, Issue 2, March - April (2013), pp. 623-631

[18] Upendra R.S, Pratima Khandelwal and Veeresh A V, Application of Artificial Neural Network Statistical Design (Ann) in Enhanced Production of Biopharmaceuticals, International Journal of Computer Engineering and Technology (IJCET), Volume 6, Issue 3, March (2015), pp. 4652

[19] Karthik Kalyan, Suvigya Jain, Dr. Ramachandra Dattatraya Lele1, Dr. Mukund Joshi and Dr. Abhay Chowdhary, Application of Artificial Neural Network Towards the Determination of Presence of Disease Conditions in Ultrasound Images of Kidney, International Journal of Computer Engineering and Technology (IJCET), Volume 4, Issue 5, September - October (2013), pp. 232-243 